\title{
Chondroitin Sulphate and Glucosamine Sulphate Synergistically Reduced DRG Proinflammatory Molecules and Improved Axonal Function in Sciatic Nerve Ligated Rats.
}

Bamidele Victor Owoyele ( $\boldsymbol{D}$ owoyele@unilorin.edu.ng )

University of llorin

Olutayo Folajimi Olaseinde

University of llorin

\section{Research Article}

Keywords: Glucosamine sulphate, Chondroitin sulphate, Neuropathic pain, Dorsal root ganglia, Gabapentin

Posted Date: October 21st, 2021

DOl: https://doi.org/10.21203/rs.3.rs-969664/v1

License: (c) (1) This work is licensed under a Creative Commons Attribution 4.0 International License. Read Full License 


\section{Abstract}

Neuropathic pain (NP) is a sickness of the somatosensory nervous system. It is linked to defective quality of life and often poorly managed. Due to the limited number of approved drugs, limited efficacy and side effects associated with them, drugs or drug combinations with great efficacy and very minimal or no side effects will be of great advantage in managing NP. This study aimed at investigating the synergistic antinociceptive effects of the combination of glucosamine sulphate (GS) $(240 \mathrm{mg} / \mathrm{kg})$ and chondroitin sulphate (CS) $(900 \mathrm{mg} / \mathrm{kg})$ in chronic constriction injury (CCI)-induced neuropathy in rat. Forty-two Wistar rats were randomly distributed into seven groups $(n=6)$. Sciatic nerve was ligated with four loose ligatures to induce NP. Effects of drugs were examined on stimulus and non-stimulus evoked potentials, expression of dorsal root ganglia (DRG) pain modulators and structural architecture of DRG. Oral administration of GS and CS for 21 days reduced hyperalgesia, allodynia, sciatic nerve functional aberration and DRG pain modulators. Histopathology and immunohistochemistry revealed restoration of structural integrity of DRG. Our result showed that the combination of GS and CS produced antinociceptive effects by attenuating hyperalgesia, allodynia and downregulation of NP mediators. GS and CS additionally produced synergistic analgesic effect than its individual components.

\section{Introduction}

Neuropathic pain (NP) is described as pain caused by an injury or sickness of the somatosensory nervous system [1]. About 7-10\% of the whole global population is affected by this debilitating condition [2]. About a fourth of people with diabetes and a third of people with HIV have neuropathic pain [3]. A recently set about systematic review of medicines for NP by international association for the study of pain (IASP) comprised of tricyclic antidepressants (TCAs), cannabinoids and serotonin and noradrenaline reuptake inhibitors (SNRIs). Most of the studies conducted in the systemic review were done in diabetic neuropathy or postherpertic neuralgia with no main focus on $\mathrm{CCl}$ of sciatic nerve. It was also reported that data did not identify one particular drug class that is superior in any particular neuropathic pain. Due to the limited number of approved drug and the efficacy of these drugs, about half of patients with NP takes concomitantly two or more drugs in managing this condition [5], thereby resulting to compliance issues. Reports have shown that drug combinations have given better results in the management of chronic neuropathic pain [6]. The frequently prescribed drugs in the management of NP such as TCAs, SNRIs and cannabinoids show moderate efficacy of at most $50 \%$ pain relief not up to a third of the patients [7]. Also, many dose limiting side effects have been associated with these drugs.

Pain mechanism is a network of knotty and constantly changing systems of sensory, cognitive and behaviour that evolved into a synchrony of protective responses to arriving noxious stimuli or stimuli that portends tissue damage or survival [8]. Glucosamine sulphate (GS) and chondroitin sulphate (CS) are compounds identified for osteoarthritis treatment. These compounds are also referred to as glycosaminoglycans (GAGs) and naturally present in the body where they form essential components of proteoglycans [9-11]. GAGs have been reported to possess anti-inflammatory, antioxidant and chondroprotective properties [11]. Hence, the study has therefore been conducted to investigate the 
synergistic effect of the combination of chondroitin sulphate and glucosamine sulphate treatment on dorsal root ganglia inflammatory markers in $\mathrm{CCl}$ neuropathic pain in male Wistar rats.

\section{Results}

Pre-surgical (baseline) behavioural test: none of the animals showed any symptoms of cold allodynia, thermal hyperalgesia or mechanical allodynia in the ipsilateral paws prior to the surgical procedure. The sciatic nerve functional index measurements were normal across all the groups prior to surgical intervention. There were no significant differences between the baseline measurements in all the various tests.

Validatory post-surgical behavioural tests: following surgical (CCl) intervention, the animals exhibited behavioural changes different from the baseline measurements, normal and sham control groups immediately the animals recovered from sedation effect of the anaesthetic drug. These behavioural changes were characterised by protective behaviour of the ipsilateral hind paw due to developed spontaneous pain stimulus. All the rats with $\mathrm{CCl}$ intervention exhibited mechanical allodynia, thermal hyperalgesia, cold allodynia and sciatic nerve functional derangement (measured via the sciatic nerve functional index). These behavioural changes were observed to be statistically $(p<0.05)$ different from the normal and sham control groups. These observations were made on the third day following $\mathrm{CCl}$ intervention.

GS and CS reversed mechanical allodynia: observations from this study showed that there was mechanical allodynia on the third day after $\mathrm{CCl}$ intervention. The mechanical allodynia was characterised by paw withdrawal from the appropriate von Frey filaments. The mechanical allodynia observed was statistically significant $(p<0.05)$ till the $24^{\text {th }}$ day in the ligated control $(L C)$ group $(11.00 \pm 0.62)$ compared to the normal $(16.33 \pm 0.61)$ and sham control groups $(16.50 \pm 0.45)$ (Fig. 1A). However, GS significantly $(p<0.05)$ reduced the observed mechanical allodynia on the $17^{\text {th }}$ day post-surgery $(12.33 \pm 0.31 \mathrm{vs}$ $10.00 \pm 0.56)$ and the $24^{\text {th }}$ day post-surgery $(13.50 \pm 0.45$ vs $10.67 \pm 0.40)$ compared to ligated control. CS significantly $(p<0.05)$ reduced the observed mechanical allodynia on the $17^{\text {th }}$ day post-surgery $(12.50 \pm 0.26$ vs $10.00 \pm 0.56)$ and the $24^{\text {th }}$ day post-surgery $(13.67 \pm 0.31$ vs $10.67 \pm 0.40)$. This was characterised by a significant increase in the paw withdrawal threshold (PWT) of the GS and CS treated rats as (Fig. 1A). Interestingly the combination of GS and CS showed a more significant reduction $(p<0.05)$ in mechanical allodynia compared to the LC animals from the $10^{\text {th }}(14.33 \pm 0.60$ vs $10.17 \pm 0.42)$, $17^{\text {th }}(14.83 \pm 0.42$ vs $10.00 \pm 0.56), 24^{\text {th }}(16.00 \pm 0.43$ vs $10.67 \pm 0.40)$ day post-CCl. This is characterised by an increase in PWT of the animals treated with the combination of GS and CS. Furthermore, the combination of GS and CS showed a synergistic and significant $(p<0.05)$ reduction in mechanical allodynia when compared when the two agents were administered singly. Animals treated with Gabapentin (GB) (reference drug) also showed a significant $(p<0.05)$ reduction in mechanical allodynia compared to the LC animals on the $10^{\text {th }}(13.17 \pm 0.49$ vs $10.17 \pm 0.42), 17^{\text {th }}(12.83 \pm 0.67$ vs $10.00 \pm 0.56)$ and $24^{\text {th }}(14.17 \pm 0.49$ vs $10.67 \pm 0.40)$ day post-CCl (Fig. 1 A). 
GS and CS reversed thermal analgesia: this study showed that thermal analgesia characterised by paw withdrawal latency from hot plate apparatus was recognised on the third day after $\mathrm{CCl}$ intervention. Thermal analgesia was significantly sustained till the $24^{\text {th }}$ day following CCI (Fig. 1B). It was observed that thermal analgesia was progressive in intensity with days. On the $3^{\text {rd }}$ day post-CCl thermal analgesia in LC group was significantly $(p<0.05)$ different from those of the normal and sham control groups, from the $3^{\text {rd }}$ to the $24^{\text {th }}$ day. However, animals treated differently with GS showed a significant $(p<0.05)$ reduction in thermal analgesia on the $17^{\text {th }}(5.99 \pm 0.31$ vs $3.70 \pm 0.17)$ and $24^{\text {th }}(6.09 \pm 0.33$ vs $2.85 \pm 0.21)$ day post $\mathrm{CCl}$ compared to the LC group. Also, animals treated differently with CS showed a significant $(p<0.05)$ reduction in thermal analgesia on the $17^{\text {th }}(6.07 \pm 0.22$ vs $3.70 \pm 0.17)(p<0.05)$ and $24^{\text {th }}$ $(6.26 \pm 0.36$ vs $2.85 \pm 0.21)$ day post $\mathrm{CCl}$. This was characterized by a withdrawal latency increase as shown in figure 1B. The combination of GS and CS showed a significant reduction in thermal analgesia from the $10^{\text {th }}(6.80 \pm 0.71$ vs $3.14 \pm 0.13), 17^{\text {th }}(7.22 \pm 0.14$ vs $3.17 \pm 0.17)$ and $24^{\text {th }}(9.49 \pm 1.48$ vs $2.85 \pm 0.21)$ day post-CCl compared to the LC group. Interestingly, the animals treated with the combination of GS and CS showed a significant reduction in thermal analgesia on the $24^{\text {th }}$ day post-CCI $(9.49 \pm 1.48 \mathrm{vs}$ $2.85 \pm 0.21)$ compared to animals treated with GS $(6.09 \pm 0.33$ vs $2.85 \pm 0.21)$ and CS $(6.26 \pm 0.36$ vs $2.85 \pm 0.21)$ individually. Animals treated with $G B$ also showed a significant $(p<0.05)$ reduction in thermal hyperalgesia compared to the LC animals on the $17^{\text {th }}(5.97 \pm 0.06$ vs $3.17 \pm 0.17)$ and $24^{\text {th }}(7.34 \pm 0.68$ vs $2.85 \pm 0.21$ ) day post-CCl (Fig. 1B).

GS and CS reversed cold allodynia: this study showed that cold allodynia characterised by increase in the duration of foot lift (DFL) to acetone drop test was observed in the LC animals and this was recognised from the $3^{\text {rd }}$ day of $\mathrm{CCl}$ intervention and significantly sustained till the $24^{\text {th }}$ day of $\mathrm{CCl}$ intervention (Fig. $2 A)$. Animals treated with GS significantly $(p<0.05)$ reduced DFL to acetone test on the $17^{\text {th }}(12.31 \pm 1.12$ vs $16.07 \pm 0.99)$ and $24^{\text {th }}(11.15 \pm 0.47$ vs $15.61 \pm 1.63)$ day post-CCl compared to the LC animals. Animals treated with CS significantly $(p<0.05)$ reduced DFL to acetone test on the $17^{\text {th }}(11.15 \pm 1.10$ vs $16.07 \pm 0.99)$ and $24^{\text {th }}(10.49 \pm 0.57$ vs $15.61 \pm 1.63)$ day post-CCl compared to the LC animals. The combination of GS and CS treatment brought about a significant $(P<0.05)$ reduction in DFL compared to the LC group on the $17^{\text {th }}(6.46 \pm 1.85$ vs $16.07 \pm 0.99)$ and $24^{\text {th }}(3.56 \pm 1.13$ vs $15.61 \pm 1.63)$ day post CCI. The combination of GS and CS treatment also brought about a synergistic significant $(P<0.05)$ reduction in $D F L$ on the $17^{\text {th }}$ $(6.46 \pm 1.85$ vs $12.31 \pm 1.12 \& 11.15 \pm 1.10)$ and $24^{\text {th }}(6.46 \pm 1.85$ vs $11.15 \pm 0.47 \& 10.49 \pm 0.57)$ day post-CCI when compared to when GS and CS were administered singly (Fig. 2A). Animals treated with GB also showed a significant $(p<0.05)$ reduction in DFL compared to the LC animals on the $17^{\text {th }}$ and $24^{\text {th }}$ day post-CCl (Fig. 2A).

GS and CS improved Sciatic nerve functional index (SFI): it was observed from this study that the baseline measurement of SFI showed no significant difference. However, following $\mathrm{CCl}$ intervention, there was a significant $(p<0.05)$ decrease in SFI $(-63.97 \pm 0.73)$ of ligated animals compared to normal $(-5.67 \pm 4.36)$ and sham $(-14.17 \pm 2.73)$ control groups (Fig. 2B). Animals treated with GS significantly $(p<0.05)$ increased SFI on the $24^{\text {th }}(-34.12 \pm 2.84$ vs $-63.04 \pm 5.17)$ day post-CCl compared to the LC 
animals. Also, Animals treated with CS significantly $(p<0.05)$ increased SFI on the $24^{\text {th }}(-28.29 \pm 1.29 \mathrm{vs}$ $-63.04 \pm 5.17)$ day post-CCl compared to the LC animals. The combination of GS and CS treatment brought about a significant $(p<0.05)$ increase in SFI compared to LC group on the $17^{\text {th }}(-29.34 \pm 3.32 \mathrm{vs}$ $-60.75 \pm 2.23)$ and $24^{\text {th }}(-19.96 \pm 0.59$ vs $-63.04 \pm 5.17)$ day post-CCI. GS and CS combination brought about a synergistic significant $(p<0.05)$ increase in SFI $(-19.96 \pm 0.59)$ on the $24^{\text {th }}$ day post-CCl when compared to administration of GS $(-34.12 \pm 2.84)$ and CS $(-28.29 \pm 1.29)$ individually (Fig. 2B).

GS and CS reversed NP modulators in the DRG: the concentration of NGF measured in the LC group was significantly $(p<0.05)$ increased $(10.32 \pm 0.37)$ compared to normal $(7.83 \pm 0.32)$ and sham $(7.84 \pm 0.32)$ control groups, while the concentration of NGF in the DRG of GS $(8.80 \pm 0.23)$ and CS treated groups was significantly $(p<0.05)$ reduced $(8.82 \pm 0.22$ vs $10.32 \pm 0.37)$ compared to LC group (Fig. 3A). The combination of GS and CS significantly $(p<0.05)$ reduced NGF concentration $(8.18 \pm 0.50$ vs $10.32 \pm 0.37)$ in the DRG compared to the LC group (Fig. 3A). GB treated animals also showed a significant $(p<0.05)$ reduction in the concentration of NGF in the DRG $(8.65 \pm 0.20$ vs $10.32 \pm 0.37)$ compared to LC group. The concentration of TNF-a measured in the DRG of LC animals was significantly $(p<.0 .05)$ increased $(6.53 \pm 0.20)$ compared to normal (5.12 \pm 0.24$)$ and sham (5.09 \pm 0.36$)$ animals (Fig. 3B.). Animals treated with GS (5.41 \pm 0.18$)$ and CS (5.26 \pm 0.20$)$ showed a significant reduction in the level of TNF-a concentration in the DRG compared to LC $(6.53 \pm 0.20)$ animals. The combination of GS and CS treatment showed a significant $(p<0.05)$ reduction in TNF-a level of DRG $(4.76 \pm 0.23$ vs $6.53 \pm 0.20)$ when compared to LC group (Fig. 3B). GB also brought about a significant ( $p<.0 .05)$ reduction in TNF-a level in DRG $(5.15 \pm 0.25$ vs $6.53 \pm 0.20)$ compared to LC group (Fig. $3 B$ ). Evaluation of the DRG level of NFKB showed a significant $(p<0.05)$ increase in the LC group $(0.0048 \pm 0.0005)$ compared to sham $(0.002 \pm 0.0004)$ and non-ligated $(0.002 \pm 0.0004)$ control groups (Fig. $3 C)$. However, GS treatment significantly $(p<0.05)$ reduced DRG level of NFKB $(0.0032 \pm 0.00017$ vs $0.0048 \pm 0.0005)$ compared to the LC group. CS treatment significantly $(p<0.05)$ reduced DRG level of NFKB $(0.0028 \pm 0.00075$ vs $0.0048 \pm 0.0005)$ compared to the LC group. The combination of GS \& CS treatment significantly $(p<0.05)$ reduced DRG level of NFKB $(0.0025 \pm 0.00022$ vs $0.0048 \pm 0.0005)$ compared to the LC group. GB treatment also reduced significantly $(p<0.05)$ the DRG level of NFKB $(0.0027 \pm 0.00056$ vs $0.0048 \pm 0.0005)$ compared to LC group (Fig. $3 C)$. The concentration of $P G E_{2}$ in the DRG of LC group was significantly $(P<0.05)$ increased $(9.30 \pm 0.58)$ compared to normal $(6.15 \pm 0.31)$ and sham (6.17 \pm 0.58$)$ control groups (Fig. 3D). However, GS treatment significantly $(p<0.05)$ reduced DRG level of $P E_{2}(6.62 \pm 0.52$ vs $9.30 \pm 0.58)$ compared to the LC group. CS treatment significantly $(p<0.05)$ reduced DRG level of $\mathrm{PGE}_{2}(6.59 \pm 0.53$ vs $9.30 \pm 0.58)$ compared to the LC group. Animals treated with the combination of GS and CS significantly $(p<0.05)$ reduced DRG level of $\mathrm{PGE}_{2}(6.34 \pm 0.67$ vs $9.30 \pm 0.58)$ compared to the LC group. Animals treated with GB showed a significant $(p<0.05)$ reduction in the DRG level of $\mathrm{PGE}_{2}(6.58 \pm 0.85$ vs $9.30 \pm 0.58)$ compared to LC group (Fig. 3D). Investigation made on the concentration of IL-1 $\beta$ in the DRG of LC animals showed significant $(p<0.05)$ increase (31.35 \pm 5.25$)$ compared to sham (15.92 \pm 2.74$)$ and non-ligated control (15.67 \pm 2.38$)$ animals (Fig. 3E). However, animals treated with GS significantly $(p<0.05)$ reduced DRG level of IL-1 $\beta(18.08 \pm 0.91$ vs $31.35 \pm 5.25)$ compared to the LC group. Animals treated with CS significantly $(p<0.05)$ reduced DRG 
level of IL-1 $\beta(17.56 \pm 1.71$ vs $31.35 \pm 5.25)$ compared to the LC group. Animals treated with the combination of GS \& CS significantly $(p<0.05)$ reduced DRG level of IL-1 $\beta(14.85 \pm 1.55$ vs $31.35 \pm 5.25)$ compared to the LC group. GB treatment showed a significant $(p<0.05)$ reduction in DRG level of IL-1 $\beta$ (14.64 \pm 1.35 vs $31.35 \pm 5.25$ ) compared to LC animals (Fig. 3E). Investigation of IL- 6 concentration in the DRG of LC group showed a significant $(p<0.05)$ reduction $(1139.00 \pm 34.01)$ compared to normal

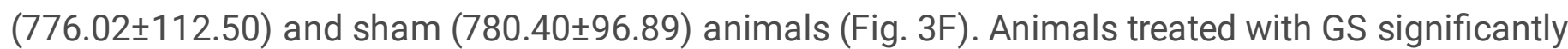
$(p<0.05)$ reduced DRG level of IL-6 $(991.70 \pm 48.87$ vs $780.40 \pm 96.89)$ compared to the LC group. Animals treated with CS showed a significant $(p<0.05)$ reduction in IL-6 level in the DRG $(975.60 \pm 71.41$ vs $780.40 \pm 96.89$ ) compared to LC group (Fi. 3F). Animals treated with the combination of GS and CS showed a significant $(p<0.05)$ reduction in the concentration of IL-6 in the DRG $(771.40 \pm 106.10$ vs 776.20 \pm 112.5 ) compared to LC group (Fig. 3F). However, GB treated animals did not show a significant reduction in the concentration of IL-6 in the DRG compared to LC group (Fig. 3F).

\section{Immunohistological examination}

$\mathrm{CCl}$ increased significantly $(\mathrm{p}<0.05)$ the expression of NFKB (Fig. 4C) in the DRG of LC group $(209.50 \pm 4.50)$ compared to non-ligated $(187.00 \pm 3.00)$ and sham $(186.00 \pm 2.00)$ control groups. The structural integrity of the DRG axons were compromised and disorganised, with increase vacuolisation, diffuse gliosis, perineural inflammation and edema in the LC group (Fig. $5 \mathrm{C}$ ). GS and CS treatment significantly $(p<0.05)$ reduced the expression of NFKB (Fig. 4) in the DRG $(184.00 \pm 4.00$ vs $209.50 \pm 4.50)$ compared to LC group. Also, increase myelination, reduced vacuolisation, reduced edema were observed in the GS \& CS treated group (Fig. 5).

\section{Discussion}

Neuropathic pain has become quite a universal burden and concern [20,21]. Sciatic nerve CCl is a well validated neuropathic pain (NP) model and it is often used in screening of possible beneficial agents against NP in animals [22]. This NP model produces pain linked behaviour that is identical to that of humans [23]. As far as we know, no related work has been done on the synergistic effect of GS and CS on $\mathrm{CCl}$ and that makes this study the first to investigate the beneficial effect of the combination of GS and $\mathrm{CS}$ in $\mathrm{CCl}$ model of NP. Neurobahavioural studies like mechanical allodynia (von Frey Filament), cold allodynia (acetone), thermal hyperalgesia (hot plate), sciatic nerve functional index (SFI) were examined respectively. Thermal hyperalgesia and Mechanical allodynia are basic symptoms of neuropathic pain that can be modelled in animal studies [22]. Biochemical parameters in the DRG were also investigated.

This study clearly showed neurohavioural derangement following $\mathrm{CCl}$ which resulted into mechanical allodynia, thermal hyperalgesia, cold allodynia and derangement in the sciatic nerve functionality. These derangements were observed on the 3rd day post-CCl and lasted throughout the period of experiment. It has been shown that rats subjected to $\mathrm{CCl}$ elicited mechanical allodynia, cold allodynia and thermal hyperalgesia [24,25]. However, treatments with GS and CS resulted in a reduced response to pain behaviour by suppressing mechanical allodynia, cold allodynia and thermal hyperalgesia by increasing 
pain thresholds. Interestingly, the combination of GS and CS treatment resulted in a synergistic reduction in pain behavioural response. In this study we observed that the combination of GS and CS showed similar efficacy as GB in suppressing pain behaviours. CCl led to a prominent loss of the hind limb function of the ipsilateral paw. This was evaluated via SFI based on the analysis of foot print. Abnormal gait was observed in $\mathrm{CCl}$ animals. This is said to be due to degradation of myelin sheath resulting to a decrease in the density of myelinated nerves which in turn negatively affects bearing as shown $(26,27)$. Myelinated neuronal loss and anomaly in posture seen after $\mathrm{CCl}$ induction may be far-fetched from neuropathic pain linked oxidative stress and neuroinflammation (27).

It has been emphasised numerous times that cytokines are signalling proteins that are crucially involved in the nervous system response to nerve injury. They function as intercellular mediator in response to nervous system injury $[28,29]$. Recently conducted experimental studies over the years have proven beyond doubt that proinflammatory cytokines can bring about or aid NP [30]. Differently, in animal model, administering anti-inflammatory drugs or cytokines or blockade of proinflammatory cytokines have lessen NP [31, 32]. The evaluation of DRG neuropathic pain markers revealed that treatments with GS, CS, the combination of GS and CS and treatment with GB reversed the concentration of NGF, PGE 2 , TNF- $a$, IL$1 \beta$, Glutamate and CGRP. IL- 6 was only reversed with the combination of GS and CS treatment. In an immunomodulatory and anti-inflammatory study in osteoarthritis, it was reported that CS a member of the GAGs exerts its beneficial effect by suppressing the generation of pro-inflammatory mediators [33, 34]. It was also reported in a non-neuropathy study on cell culture experimentation that glucosamine sulphate reduced the generation of pro-inflammatory mediators by suppressing the production of ROS and NFkB activation $[35,36]$.

A previous report showed that NGF (a member of the neurotrophins (NTs) family) plays a crucial role in the pathobiology of neuropathic pain [37]. NGF are synthesised mainly in the DRG and modulate central sensitisation by binding with neurotrophic tyrosine kinase $A$ (TrkA) receptor and pan neurotrophin receptor at $75 \mathrm{kDa}$ (p75NTR) [38]. The interaction of NGF with TrkA receptor results to signalling that activates the upregulation of transient receptor potential vanilloid 1 (TRPV1), CGRP, substance-P (SP), sodium channels $\left(\mathrm{Na}_{v} 1.8\right.$ and $\left.\mathrm{Na}_{v} 1.9\right)$ expression [37]. The interaction of NGF with p75NTR results to downstream signalling linked with NP via the c-Jun and NF-kB pathway. Also, activation of p75NTR can trigger Trk mediated signalling in NP [37]. This study showed that GS and CS and the combination of GS and CS treatments suppressed NGF level in the DRG and showed similar efficacy as GB in reducing NGF level in the DRG.

TNF-a has been reported to be involved in early degenerative changes in peripheral nerve injury [39]. These molecules are formed by Schwann cells in Wallerian degeneration process [40] and are reported to contribute to hyperalgesia and allodynia $[41,42,43]$. Furthermore, TNF-a acutely elevates Tetrodoxinresistant (TTX-R) $\mathrm{Na}^{+}$currents [44]. This modulation occurs through the activation of tumor necrosis factor receptor 1 (TNFR1) and phosphorylation of p38 (MAPK) [44]. Hence, this study showed that suppression of TNF-a following treatment with GS, CS and the combination of GS and CS reveals the beneficial effect of these GAGs in reducing mechanical allodynia, cold allodynia and thermal 
hyperalgesia. TNF-a activity has been postulated to cause an increase in primary afferent neuron excitability via reduction in currents in potassium channels or increase in currents through sodium or calcium channels $[44,45]$. NFKB, a family of DNA-binding proteins that are related in structure are variously involved in many pathological and physiological processes which include neurodegenerative diseases [46] and chronic pain [47]. Activation of NFKB involves two different pathways, which are the classical or canonical and the alternative or non-canonical pathways [48]. Evidences have shown that TNF-a is crucial in both pathways [48]. Past studies have reported that TNF-a/NFKB signalling activation results to persistent hyperexcitability of neurons in the DRG [49] via upregulation of $\mathrm{Na}^{+}$channels [50]. From this study, the level of NFKB in the DRG of CCl rats were elevated. Treatments with GS, CS and the combination of GS and CS suppressed NFKB level in the DRG. It is therefore suggested that the suppression of TNF-a in this study might be responsible for the reduced expression of NFKB observed. Cyclooxygenase (COX) enzymes (COX 1 and COX 2) have been implicated to play a crucial role in arachidonic acid pathway involved in pain exacerbation. The prostaglandins derived from arachidonic acid heightened neuronal excitability, generate and transmit pain signals. It has been confirmed that COX play an intricate role in the downstream signalling of $\mathrm{PGE}_{2}$ [51]. The same study confirmed that treatments with COX inhibitors suppresses the release of PGE2 in the DRG [51]. Studies using localised stimulation showed that injected $\mathrm{PGE}_{2}$ reduced von Frey filament threshold for mechanical allodynia [52]. It was also reported that peripheral nerve injury resulted to increase in $P_{G} E_{2}$ level in the lumbar $D R G$ and that proinflammatory cytokine IL1- $\beta$ aided production of PGE 2 in DRG neurons. Under physiologic circumstances, IL1- $\beta$ production is at low levels in the spinal cord. Following injury to the peripheral nerve, the level of IL1- $\beta$ expression is upregulated [53]. This presented study showed that the level of IL1- $\beta$ in the DRG of CCI rats was upregulated and treatments with GS and CS reduced expression of IL1- $\beta$. It is interesting to note that suppression of IL1- $\beta$ might be responsible for the reduction in the level of PGE 2 observed. Our findings showed that IL1- $\beta$ expression can result to the activation of proinflammatory molecules such as IL-6, SP, PGE 2 through complex signalling cascades [53, 54, 55]. Evidence has shown that IL1- $\beta$ just like NGF can modulate excitability of neurons via TRPV1, GABA receptors, sodium channels and NMDA receptors [43].

Data from this study revealed that the level of IL-6 in the DRG of CCI rats was elevated. Studies have shown that IL-6 is crucial in the nervous system response to injury [56, 57]. IL-6 is implicated in the survival of neurons, protection of the neuron against damage $[56,57]$ and pain modulation $[58,59]$. The level of IL-6 in the DRG is upregulated following $\mathrm{CCI}[60,61]$. It was reported that the intrathecal injection of IL-6 into the hind paw of rats brought about touch-evoked hyperalgesia [62] and mechanical allodynia [63]. These research findings suggest that IL-6 may centrally play a key role in the event cascades that leads to NP. The level of IL-6 was however reduced following treatment with the combination of GS and CS. Immunohistochemistry and histopathological study showed that the combination of GS and CS treatment reduced oedema, vacuolation, perineural inflammation and gliosis, increased proliferation of glial cells and improved overall integrity of the DRG. This improvement exerted by GS and CS was similar to that exerted by GB. 


\section{Conclusions}

this is the first study to investigate the therapeutic role of CS, GS and the combination of both GS and CS on DRG proinflammatory cytokines in a CCI model of neuropathic pain. This study has shown that CS, GS and the combination of both GS and CS can reduce mechanical allodynia, cold allodynia and thermal hyperalgesia, improve DRG neuronal functions and as well improve sciatic nerve functional index. The efficacy of CS and GS in this model is through suppression of IL1- $\beta$, NFKB, NGF, TNF-a, IL-6, PGE 2 . This study therefore suggests that the combination of GS and CS may have synergistic therapeutic potential in managing injury to the peripheral nerve.

\section{Materials And Methods}

\section{Animals}

All experimental procedures were approved by the University of Ilorin Ethical Review Committee (approval number UERC/ASN/2019/1949) and conducted in accordance with ARRIVE guidelines. Male Wistar rats weighing 150-200g, were used for the study and were housed in the Faculty of Basic Medical Sciences, University of llorin animal house. The rats were acclimatised for 2 weeks after which the experiments commenced. The animals were housed in cages made of wood, exposed to $12 \mathrm{~h}$ light/dark cycle and had unhindered access to water and food with exception to experimental procedure periods. All experimens were performed between $8 \mathrm{am}$ and $2 \mathrm{pm}$ to avoid possible diurnal variation in the behavioural tests. Pain tests or neurobehavioural test were carried out by experimenters blinded to the treatments. All efforts to minimise animal suffering and to use the minimum number of animals required to produce dependable results were employed. The animals were handled based on the laid down principle of the Guide for the Care and Use of Laboratory Animals published by National Institute of Health.

Drugs and Chemicals: Analytical grade glucosamine sulphate and chondroitin sulphate (Jiaxing Hengjie Biopharmaceutical Co., Ltd, China) were used. These drugs and their combinations were dissolved in $0.9 \% \mathrm{NaCl}$ and orally administered using oral cannula. sodium pentobarbital (50 mg/kg i.p.) (SigmaAldrich, USA) was used as anesthetic agents. Other chemicals and materials were obtained from Bridge Biotech Ltd, Nigeria. 4.0 silk suture was used to induce $\mathrm{CCl}$ and suture the muscles, while 4.0 nylon suture was used to suture the skin.

Experimental Design: Animals were randomly grouped into seven (7) groups of six rats $(n=6)$ per group with sample size determined based on $G^{*}$ power analysis [12] and the ethical concept of reduction [13]. The grouping (Fig. 1A) consists of four (4) control groups.

The non-ligated control (NC) animals received normal saline $(2.5 \mathrm{ml} / \mathrm{kg}$ oral) treatment without ligation. The sham control (SC) animals had the skin and muscle opened and sutured without nerve ligation. The sham animals were treated with $2.5 \mathrm{ml} / \mathrm{kg}$ orally administered normal saline. The $\mathrm{CCl}$ rats or the ligated control (LC) animals were induced with right sciatic nerve $\mathrm{CCl}$ and were treated with $2.5 \mathrm{ml} / \mathrm{kg}$ orally administered normal. GS treated animals underwent surgical procedure with chronic constriction of the 
right sciatic nerve and were treated with GS $(240 \mathrm{mg} / \mathrm{kg}$ oral). CS treated animals underwent surgical procedure with chronic constriction of the right sciatic nerve and were administered oral CS $(900 \mathrm{mg} / \mathrm{kg}$ oral.). GSCS treated animals underwent surgical procedure with $\mathrm{CCl}$ of the right sciatic nerve following which they were administered oral combination of GS $(240 \mathrm{mg} / \mathrm{kg})$ and CS $(900 \mathrm{mg} / \mathrm{kg})$. GB treated rats underwent surgical procedure with $\mathrm{CCl}$ of the right sciatic nerve and were treated with $60 \mathrm{mg} / \mathrm{kg}$ orally administered gabapentin (a reference control).

The treatments duration lasted for 21 days which commenced on the 3rd day post $\mathrm{CCl}$ intervention (Fig. 6).

Induction of chronic constriction injury: $\mathrm{CCl}$ model for neuropathic pain was applied to bring about neuropathy as portrayed by Bennett and Xie [14]. Under sodium pentobarbital anesthesia, incision was made on the skin of the right hind limb and the sciatic nerves underneath the biceps femoris were exposed and freed of adhering tissue and three loose ligatures of silk 4.0 were tied around it with $3 \mathrm{~mm}$ gap approximately. The sham control rats had the skin and femoris muscle opened and sutured without nerve ligation. To examine the synergistic effects, we administered a combination of GS $(240 \mathrm{mg} / \mathrm{kg})$ and CS $(900 \mathrm{mg} / \mathrm{kg})$ and investigated the effects on thermal hyperalgesia, mechanical allodynia, cold allodynia, sciatic nerve functional index and central proinflammatory markers.

Mechanical Allodynia (von Frey Test): To investigate the sensory functionality of the sciatic nerve, von Frey filament test (Ugo Basile, Italy) was used to measure paw withdrawal threshold to mechanical stimuli. The rats were housed in a transparent plastic with a mesh floor made of metal and before testing, were habituated to the environment for about 10 minutes. von Frey filaments of evaluator sizes 4.17, $4.31,4.56,4.74,4.93,5.07,5.18,5.46,5.88$ and 6.1 (corresponding to forces of $1.4 \mathrm{~g}, 2 \mathrm{~g}, 4 \mathrm{~g}, 6 \mathrm{~g}, 8 \mathrm{~g}, 10$, $15 \mathrm{~g}, 26 \mathrm{~g}, 60 \mathrm{~g}, 100 \mathrm{~g}$ respectively) were applied to the hind paw's plantar surface. Each filament was used five times for a single paw and the mechanical threshold was calculated based on the method of Bonin et al. [15].

Mechanical allodynia was determined prior to $\mathrm{CCl}$ (baseline), then $3,10,17$ and 24 days following $\mathrm{CCl}$. Drugs treatment commenced on day 3 following $\mathrm{CCl}$ after post $\mathrm{CCl}$ tests.

Thermal Hyperalgesia (Hot-Plate Test): Thermal sensitivity of the hind paw was evaluated with a hotplate apparatus (Hefe-joyce, China). The hot plate was preheated to $55^{\circ} \pm 0.5^{\circ} \mathrm{C}$ and animals were placed on the preheated plate surface. The reaction time of paw withdrawal was recorded with a cut-of time set at 20s. Thermal analgesia was determined prior to $\mathrm{CCl}$ (baseline), then 3,10,17 and 24 days following $\mathrm{CCl}$.

Cold Allodynia (Acetone Test): Latency of paw withdrawal to cold stimulus was investigated using acetone spray test as described by Yoon et al. [16]. Cold allodynia was determined prior to CCI (baseline), then $3,10,17$ and 24 days following $\mathrm{CCl}$. 
Histological Analysis: Five-ten hours after the last dose of drug treatment, rats were made unconscious and the sciatic nerve proximal to the bifurcation point was dissected. All animals were anaesthesized with sodium pentobarbital. Formalin (10\%) was used to fix the DRG, included in paraffin and put through to $7 \mu \mathrm{m}$ thick transverse sections, followed by further hematoxylin and eosin (H\&E) staining. The slides were examined by a person blinded to the treatments. The following parameters were analysed from the slides: nerve constituents, which include endoneurium, perineurium and epineurium, the nerve fiber, inflammatory cell infiltrates and Schwann cells.

\section{Biochemical analysis of the DRG}

Five to ten hours after the last dose of treatment, the spinal column was dissected from the base of the skull to the level of the femurs, it was cut down the mid-line and the spinal cord extruded and meninges removed as described by Sleigh et al. [17], L3\&L4 DRG were extracted and rinsed and stored in ice-cold phosphate buffer solution (PBS) and frozen for biochemical analysis. DRG was homogenized with the aid of a glass homogenizer at $4^{\circ} \mathrm{C}$ in ice-cold saline $(2 \mathrm{ml})(11 \mathrm{mmol} \mathrm{L}-1$ Tris buffer, $\mathrm{pH} 7.4)$. Homogenates were centrifuged at 5,000 RPM for ten minutes and supernatants were collected for the estimation of biochemical parameters using ELISA principle.

\section{Evaluation of proinflammatory mediators}

Prostaglandin $\mathrm{E}_{2}\left(\mathrm{PGE}_{2}\right)$, (Bioassay Technology Laboratory, Shanghai, China) Tumor necrotic factor alpha (TNF-a) (Elabscience Biotechnology Inc., Texas, USA), interleukin 6 (IL-6) (Elabscience Biotechnology Inc., Texas, USA), interleukin 1 beta (IL1- $\beta$ ) (Elabscience Biotechnology Inc., Texas, USA), nerve growth factor (NGF) (Bioassay Technology Laboratory, Shanghai, China) and nuclear factor kappa B-105 (NFkB105) (Elabscience Biotechnology Inc., Texas, USA) levels in the DRG homogenate were assessed using ELIZA techniques based on the manufacturer's instructional manual.

\section{Histological evaluation}

DRG tissue (L5) was investigated using haematoxylin and eosin stain (H\&E). Histological examination of slide was as described by Windsor [18] and Hopwood [19]. The DRG tissues were fixed in $10 \%$ formalin for over 24 hours before dehydrating, clearing, embedding and staining.

Immunohistochemistry: Expression of nuclear factor kappa B (NFkB p65) was evaluated using the Thermo Scientific Pierce Peroxidase IHC Detection Kit (36000, Thermo Sciencific, USA) with modest procedure modification. Endogenous peroxidase activity was quenched by incubating tissue for 30 minutes in Peroxidase Suppressor, washed three times in Wash Buffer. Blocking buffer was added to the slides and incubated for 30 minutes. Excess buffer was blotted from the tissue sections, before addition of primary antibodies; NFkB p65 (Cat \#14-6731-81, Thermo Sciencific, USA), at a dilution of 1:100 and left overnight in a humidified chamber at $4^{\circ} \mathrm{C}$. Afterward, slides were washed two times for 3 minutes with Wash Buffer. 
The tissue sections were treated with Biotinylated Secondary Antibody and incubated for 30 minutes. The slides washed three times for 3 minutes each with Wash Buffer, treated and incubated with the Avidin/Streptavidin-HRP for another 30 minutes, and washed three times for 3 minutes each with Wash Buffer. The tissues were incubated with Metal Enhanced DAB (3.3 diaminobenzidine) Substrate Working Solution for 5 minutes for desired staining to be achieved. The slides were rinsed with distilled water and drained. Adequate amount of Mayer's hematoxylin stain was dropped on to the slide to cover the entire tissue surface and incubated for 1-2 minutes at room temperature. Drained off the hematoxylin and washed slide several times with distilled water. The slides were mounted and photomicrographed with Amscope MU900 digital camera attached to the microscope. The intensity of staining was examined with the open-source Fiji (ImageJ) software.

\section{Statistical analysis}

GraphPad Prism 8.0.1 software (USA) was used for statistical analyses. Values are expressed as Mean \pm S.E.M. Behavioural data were analysed using one way and two-way analysis of variance (ANOVA) with Tukey's post hoc multiple comparisons test. Biomarkers data were analysed with one-way ANOVA followed by Turkey's post hoc multiple comparisons test. $\mathrm{P}<0.05$ are considered significant.

\section{Declarations}

\section{Acknowledgment}

Authors are appreciative of the members of the neuroscience unit of the University of Ilorin, and members of Bridge Biotech Ltd who supported in some parts of the laboratory work.

\section{Authors contribution}

B.V.O. and O.O.F. conceived and designed the study. O.O.F. conducted experiments and data analysis. B.V.O. and O.O.F. contributed to reagents and assessment tools. B.VO. supervised the study. B.V.O and O.O.F. wrote the manuscript. All authors read and approved the manuscript. Data were generated in-house without using any paper mill.

\section{Funding}

There was no grant received by the researchers the study. It was self-financed.

\section{Clash of interests}

The authors acknowledge no clash of interest.

\section{Data availability statement}

Th data supporting the findings from this study are available on request from the corresponding author. 


\section{References}

1. International Association for the Study of Pain. IASP Taxonomy (2018) Pain terms. Neuropathic pain. 2017. Dec 14. www.iasp-pain.org/Taxonomy Neuropathic pain [cited 2018 May 1].

2. Colloca L, Ludman T, Bouhassira D et al. (2017) "Neuropathic pain." Nature Reviews Disease Primers 3(1): 17002. DOI: 10.1038/nrdp.2017.2. PMID: 28205574

3. International Association for the Study of Pain (2014) Epidemiology of neuropathic pain: how common is neuropathic pain, and what is its impact? Washington: IASP; 2014. https://www.iasppain.org/Advocacy/Content. aspx?ItemNumber=3934 [cited 2018 May 1]

4. Murnion B. (2018) Neuropathic pain: Current definition and review of drug treatment Article in Australian Prescriber 41: 3. DOI: 10.18773/austprescr.2018.022. PMID: 29921999

5. Moore RA, Derry CJ, Derry S, Straube S, McQuay HJ (2012) A conservative method of testing whether combination analgesics produce additive or synergistic effects using evidence from acute pain and migraine. European Journal of Pain 16(4): 585-591. DOI: 10.1016/j.ejpain.2011.08.009. PMID: 22396086.

6. Chaparro LE, Wiffen PJ, Moore RA, Gilron I (2012) Combination pharmacotherapy for the treatment of neuropathic pain in adults. Cochrane Database of Systematic Reviews. Issue 7. Art. No.: CD008943. DOI: 10.1002/14651858.CD008943.pub2. PMID: 22786518.

7. Finnerup NB, Sindrup SH, Jensen TS (2010) The evidence for pharmacological treatment of neuropathic pain. Pain. 150:573-81. An important neuropathic pain treatment algorythm. DOI: 10.1016/j.pain.2010.06.019. PMID: 20705215

8. Melzack R. (1999) From the gate to the neuromatrix. Pain Suppl 6: S121-126. PMID: 10491980. DOI: 10.1016/S0304-3959(99)00145-1

9. Martel-Pelletier J, Boileau C, Pelletier JP, et al. (2008) Cartilage in normal and osteoarthritis conditions. Best Pract Res Clin Rheumatol. 22: 351-84. DOI: 10.1016/j.berh.2008.02.001. PMID: 18455690.

10. Hardingham $T$ (2008) Extracellular matrix and pathogenic mechanisms in osteoarthritis. Curr Rheumatol Rep. 10: 30-6. DOI: 10.1007/s11926-008-0006-9. PMID: 18457609.

11. du Souich P, García AG, Vergés J, \& Montell E (2009) Immunomodulatory and anti-inflammatory effects of chondroitin sulphate. Journal of cellular and molecular medicine, 13(8A), 1451-1463. DOI: 10.1111/j.1582-4934.2009.00826.x PMID: 19522843

12. Faul F, Erdfelder E, Lang AG, Buchner A (2007) G*Power 3: A flexible statistical power analysis program for the social, behavioural and biochemical sciences. Behav Res Methods 39:175-91. DOI: 10.3758/bf03193146. PMID: 17695343.

13. Zimmermann M (1983) Ethical guidelines for investigations of experimental pain in conscious animals. Pain 16(2): 109-110. DOI: 10.1016/0304-3959(83)90201-4. PMID: 6877845.

14. Bennett GJ, Xie YK (1988) A peripheral mononeuropathy in rat that produces disorders of pain sensation like those seen in man. Pain 33: 87-107. DOI: 10.1016/0304-3959(88)90209-6. PMID: 
2837713

15. Bonin RP, Bories C, De Koninck YA (2014) Simplified up-down method (SUDO) for measuring mechanical nociception in rodents using von Frey filaments. Mol Pain 10: 26. DOI: 10.1186/17448069-10-26. PMID: 24739328

16. Yoon C, Yoon YW, Na HS, Kim SH, Chung JM (1994) Behavioral signs of ongoing pain and cold allodynia in a rat model of neuropathic pain. Pain 59: 369 -376. DOI: 10.1016/0304-3959(94)90023X. PMID: 7708411

17. Sleigh JN, West SJ, Schiavo G. A video protocol for rapid dissection of mouse dorsal root ganglia from defined spinal levels. BMC Res Notes. 2020 Jun 24;13(1):302. DOI: 10.1186/s13104-02005147-6. PMID: 32580748

18. Windsor $L$ (1994) Tissue processing, in Laboratory histopathology, a complete reference (Woods, A.E., and Ellis, R.C., eds), Churchill Livingstone, New York 1: 4.2-1/4.2-42.

19. Hopwood D (1996) Fixation and fixatives. In Bancroft J and Stevens A eds. Theory and practice of histological techniques. New York: Churchill Livingstone.

20. van Hecke O, Austin SK, Khan RA, Smith BH, Torrance N (2014) Neuropathic pain in the general population: a systematic review of epidemiological studies. Pain 155(4):654-662. DOI: 10.1016/j.pain.2013.11.013. PMID: 24291734.

21. Jensen TS, Baroschn R, Haanpää M et al. (2011) A new definition of neuropathic pain. Pain 152:2204-2205. DOI: 10.1016/j.pain.2011.06.017. PMID: 21764514.

22. Jaggi AS, Jain V, and Singh N (2011) "Animal models of neuropathicpain," Fundamental \& Clinical Pharmacology 25 (1): 1-28. DOI: 10.1111/j.1472-8206.2009.00801.x. PMID: 20030738.

23. Van der Wal S, Cornelissen L, Behet M, Vaneker M, Steegers M, and Vissers K. (2015) "Behavior of neuropathic pain in mice following chronic constriction injury comparing silk and catgut ligatures," SpringerPlus 4 (1): 225. DOI: 10.1186/s40064-015-1009-4. PMID: 26069872

24. Owoyele BV, Bakare AO (2018) Analgesic properties of aqueous bark extract of Adansonia digitata in Wistar rats. Biomed Pharmacother 97: 209-12. DOI: 10.1016/j.biopha.2017.10.079. PMID: 31888313

25. Guida F, De Gregorio D, Palazzo E, Ricciardi F, Boccella S, Belardo C, lannotta M, Infantino R, Formato F, Marabese I, Luongo L, de Novellis V, Maione S (2020) Behavioral, Biochemical and Electrophysiological Changes in Spared Nerve Injury Model of Neuropathic Pain. Int J Mol Sci. 21(9):3396. DOI: 10.3390/ijms21093396. PMID: 32403385.

26. Arruri V, Komirishetty P, Areti A, Dungavath S \& Kumar A (2017) Nrf2 and NF-kB modulation by Plumbagin attenuates functional, behavioural and biochemical deficits in rat model of neuropathic pain. Pharmacological reports 69(4):625-632. DOI: 10.1016/j.pharep.2017.02.006. PMID: 28505604.

27. Komirishetty P, Areti A, Gogoi R, Sistla R, Kumar A (2016) Poly (ADP-ribose) polymerase inhibition reveals a potential mechanism to promote neuroprotection and treat neuropathic pain. Neural Regen Res. 11(10):1545-1548. DOI: 10.4103/1673-5374.193222. PMID: 27904474.

28. Jančálek R, Dubový P, Svíženská I. et al. (2010) Bilateral changes of TNF-a and IL-10 protein in the lumbar and cervical dorsal root ganglia following a unilateral chronic constriction injury of the sciatic 
nerve. J Neuroinflammation 7: 11 DOI:10.1186/1742-2094-7-11. PMID: 20146792

29. Rothwell NJ, Hopkins SJ (1995) Cytokines and the nervous system II: Actions and mechanisms of action. Trends Neurosci 18:130-136. DOI:10.1016/0166-2236(95)93890-A. PMID: 7754524

30. Scholz J, Woolf CJ. The neuropathic pain triad: neurons, immune cells and glia. Nat Neurosci. 2007 Nov;10(11):1361-8. DOI: 10.1038/nn1992. PMID: 17965656.

31. Milligan ED, Sloane EM, Langer SJ, Cruz PE, Chacur M, Spataro L, Wieseler-Frank J, Hammack SE, Maier SF, Flotte TR, Forsayeth JR, Leinwand LA, Chavez R, Watkins LR. (2005) Controlling neuropathic pain by adeno-associated virus driven production of the anti-inflammatory cytokine, interleukin-10. Mol Pain 1:9. DOI: 10.1186/1744-8069-1-9. PMID: 15813997.

32. Zahn PK, Subieta A, Park SS, Brennan TJ. (2004) Effect of blockade of nerve growth factor and tumor necrosis factor on pain behaviors after plantar incision. J Pain. 5(3):157-63. DOI: 10.1016/j.jpain.2004.02.538. PMID: 15106128.

33. Monfort J, Pelletier JP, Garcia-Giralt N et al. (2008) Biochemical basis of the effect of chondroitin sulphate on osteoarthritis articular tissues. Ann Rheum Dis. 67: 735-40. DOI:

10.1136/ard.2006.068882. PMID: 17644553.

34. Legendre F, Bauge $C$, Roche R, et al. (2008) Chondroitin sulfate modulation of matrix and inflammatory gene expression in IL-1 beta-stimulated chondrocytes-study in hypoxic alginate bead cultures. Osteoarthritis Cartilage. 2008; 16: 105-14. DOI: 10.1016/j.joca.2007.05.020 PMID:

\section{4}

35. Chiu, HW., Li, LH., Hsieh, CY. et al. (2019) Glucosamine inhibits IL-1 $\beta$ expression by preserving mitochondrial integrity and disrupting assembly of the NLRP3 inflammasome. Sci Rep 9(1): 5603. DOI:10.1038/S41598-019-42130-Z. PMID: 30944389

36. Cañas N, Gorina R, Planas AM, Vergés J, Montell E, García AG, López MG. (2010) Chondroitin sulfate inhibits lipopolysaccharide-induced inflammation in rat astrocytes by preventing nuclear factor kappa B activation. Neuroscience 167: 872-879. DOI: 10.1016/j.neuroscience.2010.02.069. PMID: 20206237.

37. Khan N, Smith MT. (2015) Neurotrophins and Neuropathic Pain: Role in Pathobiology. Molecules. 20(6):10657-10688. DOI: 10.3390/molecules200610657. PMID: 26065639

38. Patapoutian A, Reichardt LF. (2001) Trk receptors: mediators of neurotrophin action. Curr Opin Neurobiol. 11(3):272-80. DOI: 10.1016/s0959-4388(00)00208-7. PMID: 11399424.

39. Shamash S, Reichert F, Rotshenker S. (2002) The cytokine network of Wallerian degeneration: tumor necrosis factor-alpha, interleukin-1alpha, and interleukin-1beta. J Neurosci. 22(8):3052-60. DOI: 10.1523/JNEUROSCI.22-08-03052.2002. PMID: 11943808.

40. Wagner R, Myers RR. (1996) Schwann cells produce tumor necrosis factor alpha: expression in injured and non-injured nerves. Neuroscience 73(3):625-9. DOI: 10.1016/0306-4522(96)00127-3. PMID: 8809782.

41. Sorkin LS, Doom CM. (2000) Epineurial application of TNF elicits an acute mechanical hyperalgesia in the awake rat. J Peripher Nerv Syst. 5(2):96-100. DOI: 10.1046/j.1529-8027.2000.00012.x. PMID: 
10905468.

42. Sommer C, Schäfers M. (1998) Painful mononeuropathy in C57BL/Wld mice with delayed wallerian degeneration: differential effects of cytokine production and nerve regeneration on thermal and mechanical hypersensitivity. Brain Res. 784(1-2):154-62. DOI: 10.1016/s0006-8993(97)01327-9. PMID: 9518588.

43. Schäfers M, Sorkin L. (2008) Effect of cytokines on neuronal excitability. Neurosci Lett. 437(3):18893. DOI: 10.1016/j.neulet.2008.03.052. PMID: 18420346.

44. Jin X, Gereau RW 4th. (2006) Acute p38-mediated modulation of tetrodotoxin-resistant sodium channels in mouse sensory neurons by tumor necrosis factor-alpha. The Journal of Neuroscience: The Official Journal of the Society for Neuroscience. 26(1):246-255. DOI: 10.1523/jneurosci.385805.2006. PMID: 16399694.

45. Czeschik JC, Hagenacker T, Schäfers M, Büsselberg D. (2008) TNF-alpha differentially modulates ion channels of nociceptive neurons. Neurosci Lett. 434(3):293-8. DOI: 10.1016/j.neulet.2008.01.070. PMID: 18314270.

46. Srinivasan M, and Lahiri DK. (2015). Significance of NF-kappaB as a pivotal therapeutic target in the neurodegenerative pathologies of Alzheimer's disease and multiple sclerosis. Expert Opin. Ther. Targets 19, 471-487. DOI: 10.1517/14728222.2014.989834. PMID: 25652642

47. Niederberger E, and Geisslinger G. (2008). The IKK-NF-kappaB pathway: a source for novel molecular drug targets in pain therapy? FASEB J. 22, 3432-3442. DOI: 10.1096/fj.08-109355. PMID: 18559989

48. Wajant $H$, and Scheurich P. (2011). TNFR1-induced activation of the classical NF-kappaB pathway. FEBS J. 278, 862-876. DOI: 10.1111/j.1742-4658.2011.08015.x. PMID: 21232017.

49. He XH, Zang Y, Chen X, Pang RP, Xu JT, Zhou X, Wei XH, Li YY, Xin WJ, Qin ZH, et al. (2010). TNFalpha contributes to upregulation of Nav1.3 and Nav1.8 in DRG neurons following motor fiber injury. Pain 151, 266-279. DOI: 10.1016/j.pain.2010.06.005. PMID: 20638792.

50. Xie M, Zhang X, Xu J, Zeng W, Li D, Xu T, Pang R, Ma K, and Liu X (2019) Nuclear factor-kappa B gates Nav1.7 channels in DRG neurons via protein-protein interaction. iScience 19,623-633. DOI: 10.1016/j.isci.2019.08.017 PMID: 31446225

51. Vellani V, Franchi S, Prandini M, Moretti S, Castelli M, Giacomoni C, Sacerdote P. (2013) Effects of NSAIDs and paracetamol (acetaminophen) on protein kinase $C$ epsilon translocation and on substance $P$ synthesis and release in cultured sensory neurons. J Pain Res. 6:111-20. DOI: 10.2147/JPR.S36916. PMID: 23429763

52. Junger H, Sorkin LS. (2000) C-nociceptor sensitization by isoprostanes is cyclooxygenase dependent. Brain Res. 867(1-2):255-8. DOI: 10.1016/s0006-8993(00)02306-4. PMID: 10837823.

53. Amaya F, Samad TA, Barrett L, Broom DC, Woolf CJ. (2009) Periganglionic inflammation elicits a distally radiating pain hypersensitivity by promoting COX-2 induction in the dorsal root ganglion. Pain. 142(1-2):59-67. DOI: 10.1016/j.pain.2008.11.013. PMID: 19135800.

54. Kawasaki Y, Xu ZZ, Wang X, Park JY, Zhuang ZY, Tan PH, Gao YJ, Roy K, Corfas G, Lo EH, Ji RR. (2008) Distinct roles of matrix metalloproteases in the early- and late-phase development of 
neuropathic pain. Nat. Med 14:331-33. DOI: 10.1038/nm1723. PMID: 18264108.

55. Bakare AO, Owoyele BV. (2021) Bromelain reduced pro-inflammatory mediators as a common pathway that mediate antinociceptive and anti-anxiety effects in sciatic nerve ligated Wistar rats. Sci Rep. 11(1):289. DOI: 10.1038/s41598-020-79421-9. PMID: 33432004.

56. Liu Z, Qiu YH, Li B, Ma SH, Peng YP (2011) Neuroprotection of interleukin-6 against NMDA-induced apoptosis and its signal-transduction mechanisms. Neurotox Res. 19(3):484-95. doi:

10.1007/s12640-010-9215-x. PMID: 20717763

57. Yang P, Wen HZ, Ou S, Cui J, Fan DH. (2012) IL-6 promotes regeneration and functional recovery after cortical spinal tract injury by reactivating intrinsic growth program of neurons and enhancing synapse formation. Exp Neurol 236(1):19-27. DOI: 10.1016/j.expneurol.2012.03.019. PMID: 22504113

58. Arruda JL, Sweitzer SA, Rutkowski MD, DeLeo JA. (2000) Intrathecal anti-IL-6 antibody and IgG attenuates peripheral nerve injury-induced mechanical allodynia in the rat: possible immune modulation in neuropathic pain. Brain Res. 879(1-2):216-225. DOI: 10.1016/s0006-8993(00)028079. PMID: 11011025.

59. Vissers KC, De Jongh RF, Hoffmann VL, Meert TF (2005) Exogenous interleukin-6 increases cold allodynia in rats with a mononeuropathy. Cytokine. 30(4):154-9. DOI: 10.1016/j.cyto.2005.01.008. PMID: 15863388.

60. Murphy PG, Borthwick LS, Johnston RS, Kuchel G, Richardson PM. (1999a) Nature of the retrograde signal from injured nerves that induces interleukin-6 mRNA in neurons. J Neurosci. 19(10):37913800. DOI: 10.1523/JNEUROSCI.19-10-03791.1999. PMID: 10234011

61. Murphy PG, Ramer MS, Borthwick L, Gauldie J, Richardson PM, Bisby MA. (1999b) Endogenous interleukin-6 contributes to hypersensitivity to cutaneous stimuli and changes in neuropeptides associated with chronic nerve constriction in mice. Eur J Neurosci. 11(7):2243-2253. DOI: 10.1046/j.1460-9568.1999.00641.

62. DeLeo JA, Colburn RW, Nichols M, Malhotra A. (1996) Interleukin-6-mediated hyperalgesia/allodynia and increased spinal IL-6 expression in a rat mononeuropathy model. $J$ Interferon Cytokine Res. 16(9):695-700. DOI: 10.1089/jir.1996.16.695. PMID: 8887053

63. Cunha FQ, Poole S, Lorenzetti BB, Ferreira SH. (1992). The pivotal role of tumor-necrosis-factor-alpha in the development of inflammatory hyperalgesia. Brit J Pharmacol. 107(3):660-664. DOI: 10.1111/j.1476-5381.1992.tb14503.x. PMID: 1472964

\section{Figures}



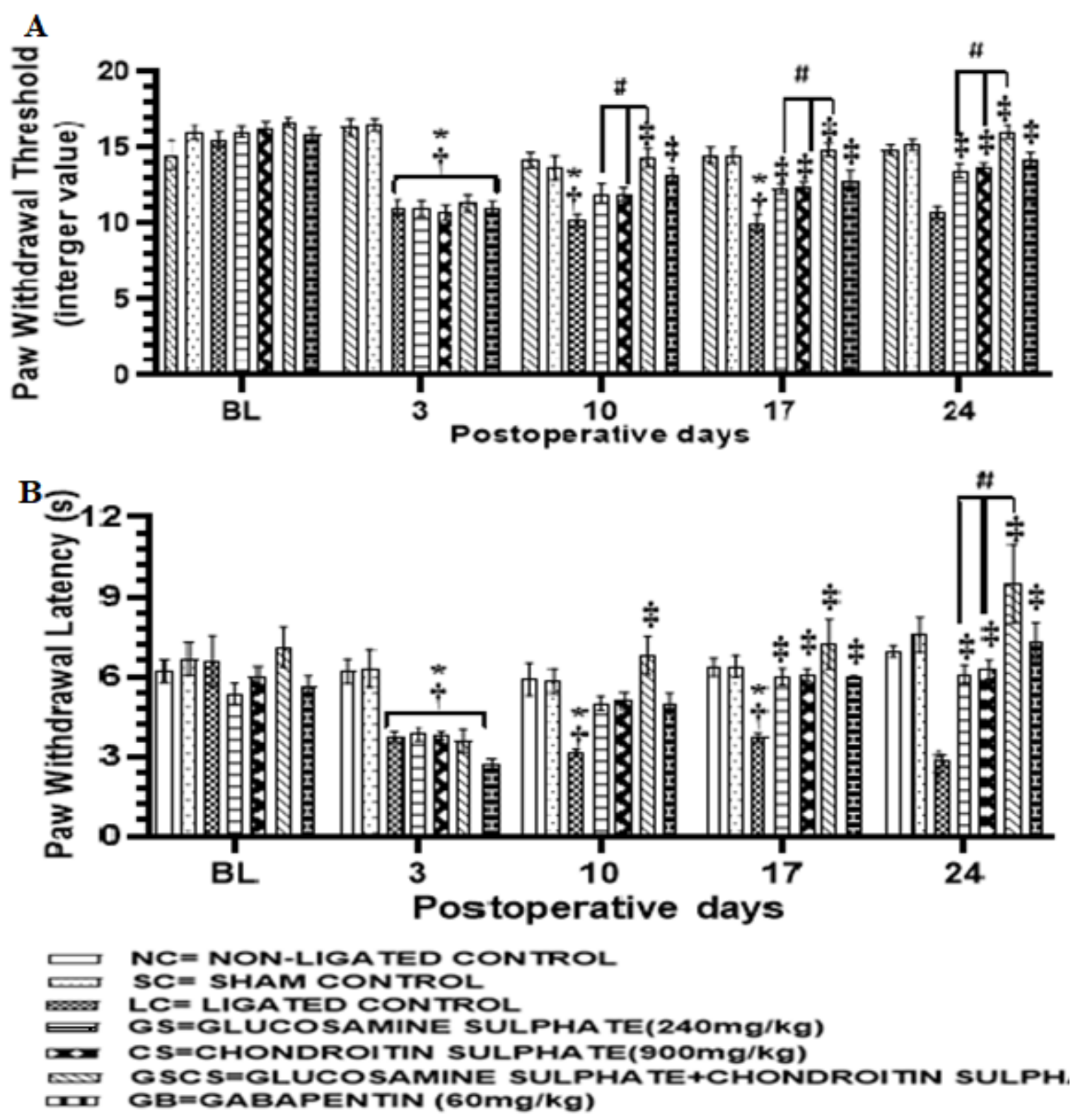

Figure 1

GS and CS reversed both mechanical allodynia and thermal hyperalgesia in sciatic nerve $\mathrm{CCl}$ model of neuropathic pain. (A) Mechanical allodynia test (B) Thermal analgesia tests. Values are shown as the mean \pm SEM ( $n=6$ for each group) ( ${ }^{\star}+\neq \# p<0.05$. *Significant versus NC., + Significant versus SC., $\neq$ Significant versus LC. \#Significant versus GSCS. BL:baseline threshold). 

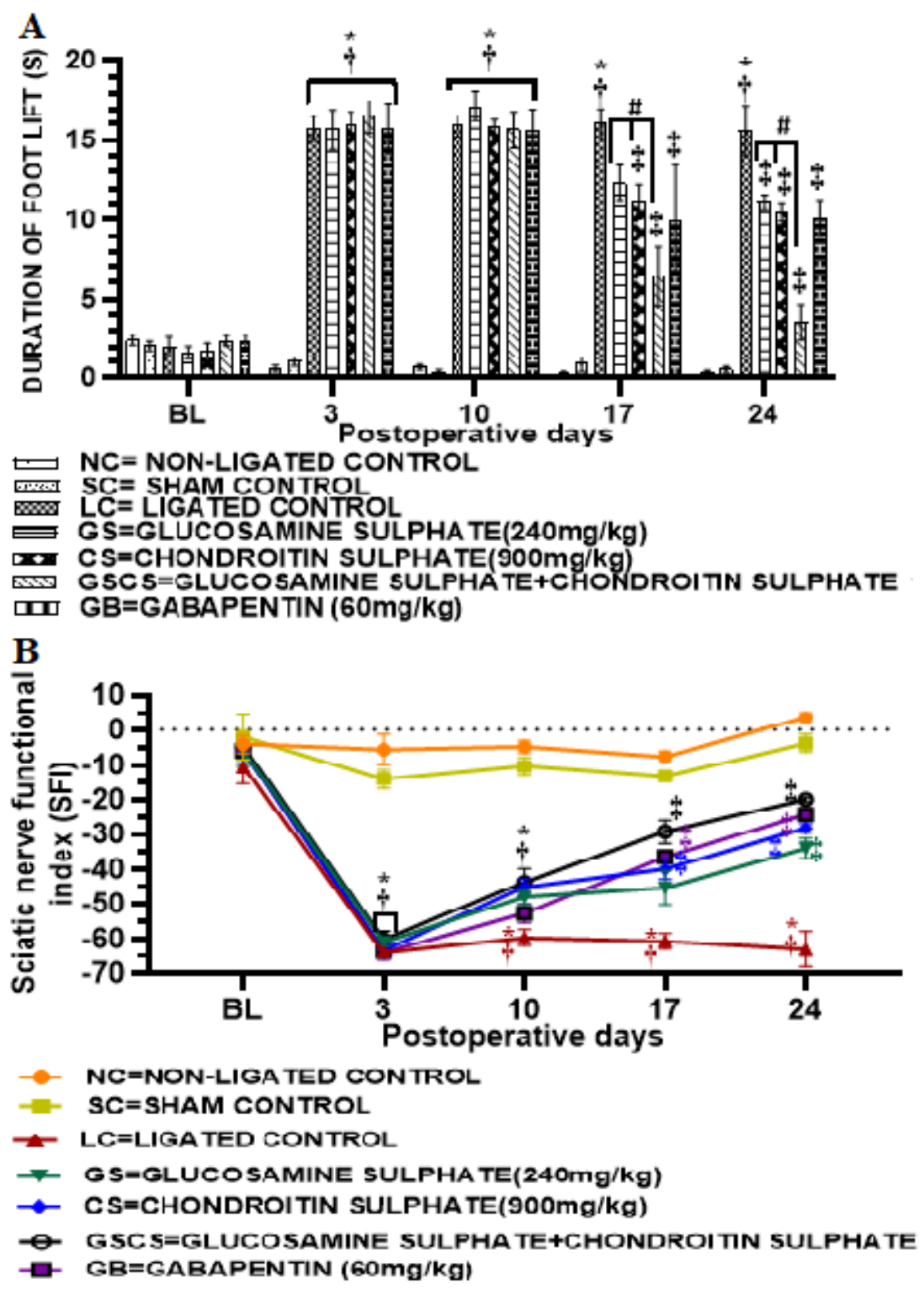

Figure 2

GS and CS reversed cold allodynia and SFI in sciatic nerve CCI model of neuropathic pain. (A) Cold allodynia test (B) SFI. Values are shown as the mean \pm SEM ( $n=6$ for each group) $\left({ }^{\star}+\ddagger \# p<0.05\right.$. *Significant versus NC., †Significant versus SC., ¥Significant versus LC., \#Significant versus GSCS. BL:baseline threshold). 

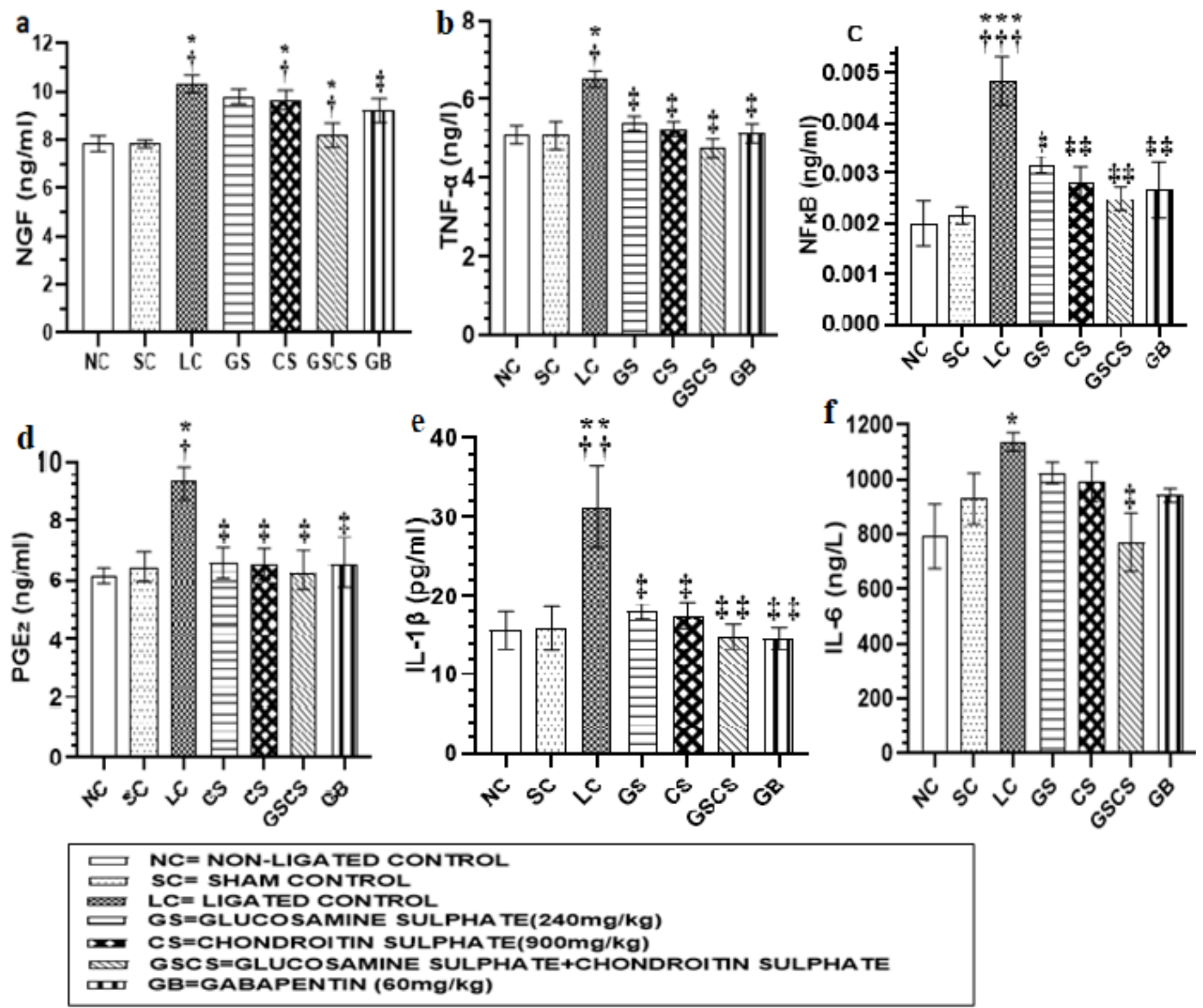

Figure 3

GS and CS reversed proinflammatory mediators in sciatic nerve CCI model of neuropathic pain. (A) NGF (B)TNF-a (C) NFKB (D) PGE2 (E) IL-1 $\beta$ (F) IL-6. Values are shown as the mean \pm SEM ( $n=6$ for each group)

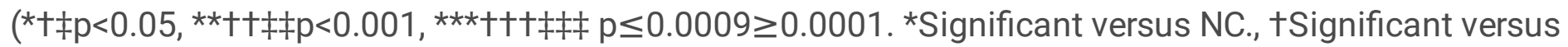
SC., ¥Significant versus LC). 

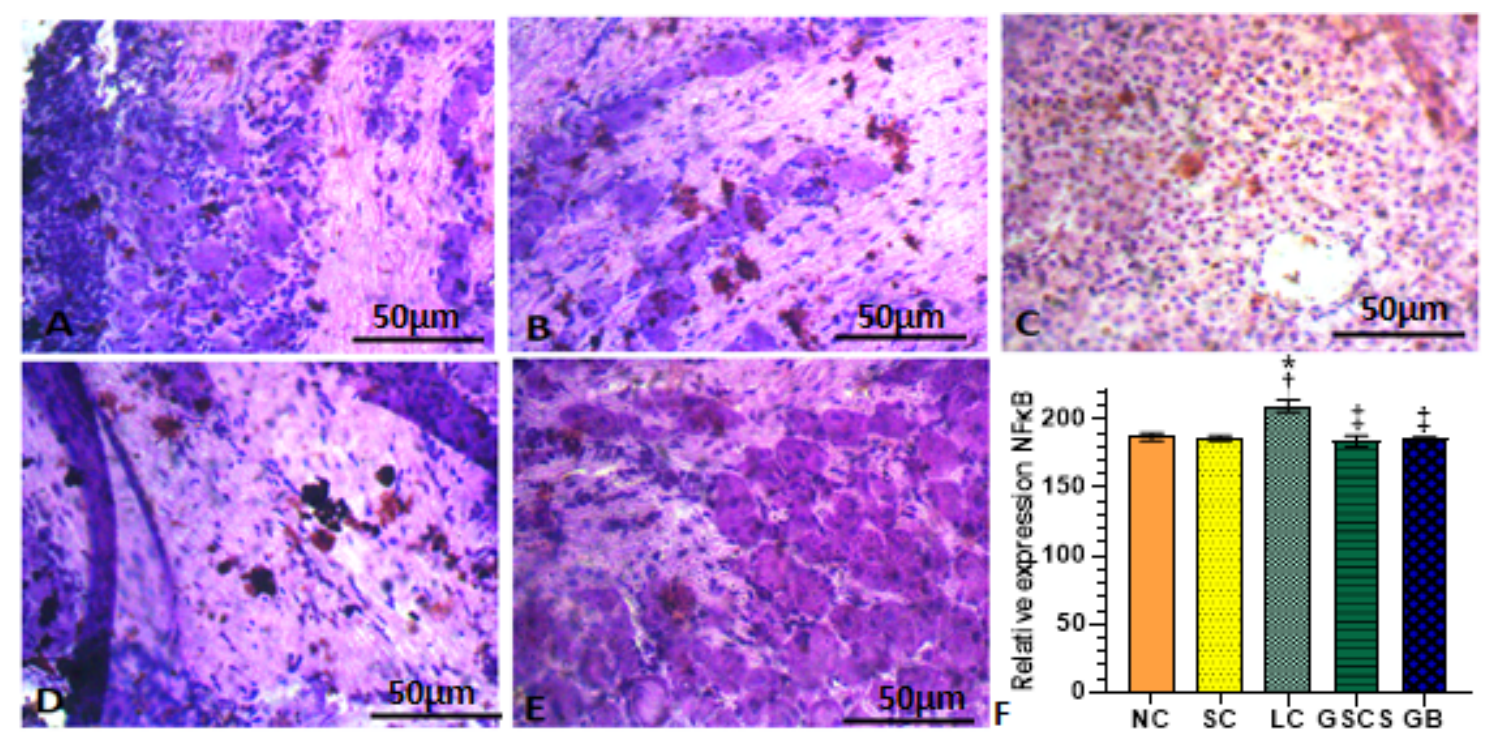

\section{Figure 4}

The combination of GS \& CS treatment reduced relative expression of NFKB in sciatic nerve CCI model of neuropathic pain. (A) NC (B)SC (C) LC (D) GSCS (E) GB (F) relative expression of NFKB. Values are shown as the mean \pm SEM ( $n=6$ for each group). ${ }^{*}+\neq p<0.05$ *Significant versus NC., + Significant versus SC., $\ddagger$ Significant versus LC.).
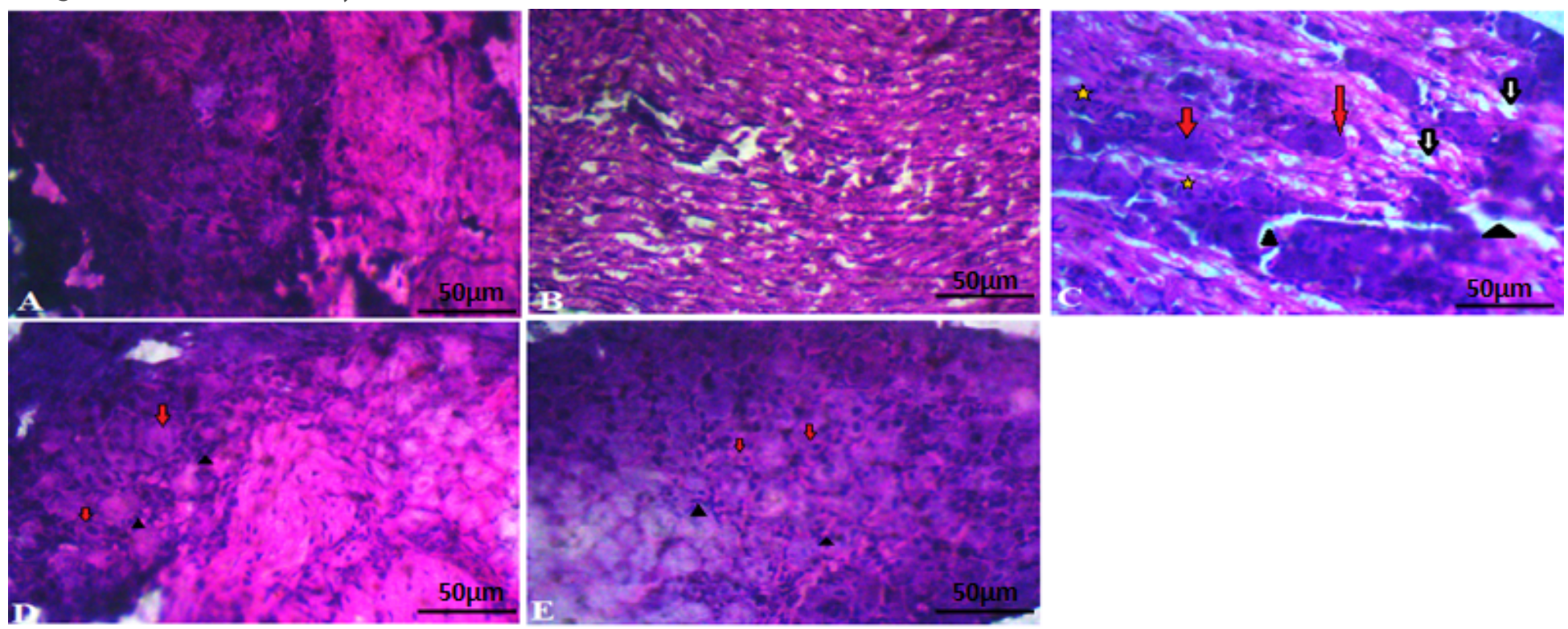

\section{Figure 5}

The combination of GS \& CS treatment improved neuronal myelination in DRG in CCI model of neuropathic pain. Hematoxylin and eosin (H\&E) preparation of lumbar DRG at $x 400$ magnification. (A) NC (B)SC (C) LC shows diffuse gliosis, edema (arrow head), vacuolation (black arrow), degenerated myelin sheath (star), perineural inflammation (red arrow) (D) Co-administration of GS \& CS attenuated edema, gliosis, vacuolation, perineural inflammation and myelin sheet degeneration, shows proliferation of glial 
cells (arrow head) and intact perineural sheet (red arrow) (E) GB shows proliferation of glial cells (arrow head) and intact perineural sheet (red arrow).

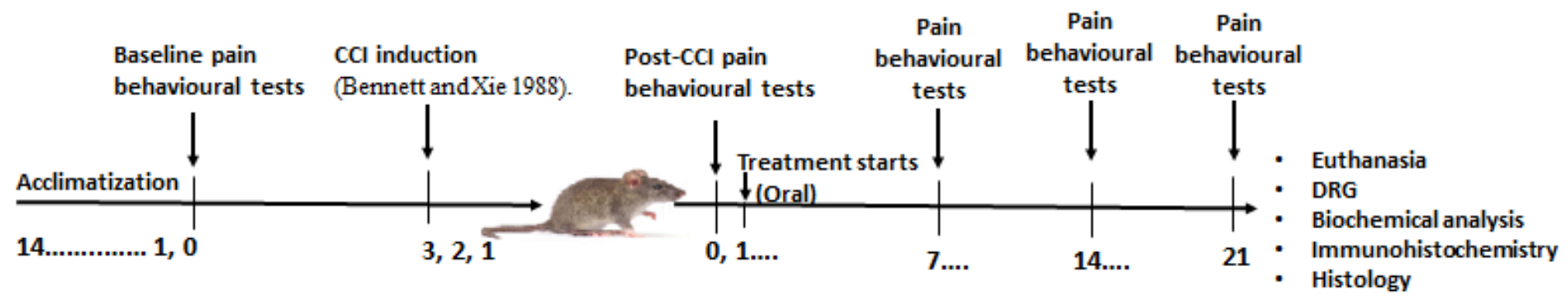

\begin{tabular}{|c|c|c|c|c|c|c|}
\hline $\begin{array}{l}\text { Non-ligated } \\
\text { control (NLC) }\end{array}$ & $\begin{array}{l}\text { Sham control } \\
\text { (SC) }\end{array}$ & $\begin{array}{l}\text { Ligated control } \\
\text { (LC) }\end{array}$ & GS & $\mathrm{CS}$ & $\mathrm{GS}+\mathrm{CS}$ & $\begin{array}{l}\text { Gabapentin } \\
\text { (GB) }\end{array}$ \\
\hline $\begin{array}{l}\text { Normal } \\
\text { saline } \\
2.5 \mathrm{ml} / \mathrm{kg} / \text { day }\end{array}$ & $\begin{array}{l}\text { Normal } \\
\text { saline } \\
2.5 \mathrm{ml} / \mathrm{kg} / \text { day }\end{array}$ & $\begin{array}{l}\text { Normal } \\
\text { saline } \\
2.5 \mathrm{ml} / \mathrm{kg} / \text { day }\end{array}$ & $\begin{array}{l}\text { Glucosamine } \\
\text { sulphate (GS) } \\
240 \mathrm{mg} / \mathrm{kg} / \text { day }\end{array}$ & $\begin{array}{l}\text { Chondroitin } \\
\text { sulphate (CS) } \\
240 \mathrm{mg} / \mathrm{kg} / \text { day }\end{array}$ & $\begin{array}{l}\text { Glucosamine } \\
\text { sulphate } \\
240 \mathrm{mg} / \mathrm{kg} \text { and } \\
\text { Chondroitin } \\
\text { sulphate } \\
900 \mathrm{mg} / \mathrm{kg}\end{array}$ & $\begin{array}{l}\text { Gabapentin } \\
60 \mathrm{mg} / \mathrm{kg} / \text { day } \\
\text { (reference } \\
\text { control) }\end{array}$ \\
\hline
\end{tabular}

Rats $(n=6 ; 150 \mathrm{~g}-200 \mathrm{~g})$

Figure 6

Schematic representation of animal grouping, treatments, $\mathrm{CCl}$ induction, drug treatments period and neurobehavioural tests schedule. 